\title{
Anaphylactic reaction following administration of topical eyedrops
}

\author{
Tina Yu Ting Shen ${ }^{1}$. Blanche X. H. Lim ${ }^{1,2}$ - Dawn K. A. Lim ${ }^{1,2} \cdot$ Chris H. L. Lim ${ }^{1,2,3,4}$ (C) \\ Received: 24 March 2021 / Accepted: 1 April 2021 / Published online: 20 April 2021 \\ (C) The Author(s), under exclusive licence to Canadian Association of Emergency Physicians (CAEP)/ Association Canadienne de Médecine d'Urgence \\ (ACMU) 2021
}

Keywords Allergies · Anaphylaxis · Topical eye drops

Dear Editor,

We would like to bring to attention a patient who developed an anaphylactic reaction following administration of eyedrops. Topical eyedrops, including anaesthetics, mydriatics, cycloplegics, and diagnostic stains, are frequently administered for a routine eye examination. Adverse reactions are rare and when present, manifest commonly as mild localised allergic reactions which resolve with discontinuation of the offending agent [1]. Few reports have documented systemic allergic reactions to these routinely administered eyedrops [2-4] which could prove fatal.

A 42-year-old Chinese lady presented to the emergency department complaining of right eye discomfort. She had documented allergies to paracetamol and a recent anaphylactic reaction to buckwheat. Initial skin prick tests further confirmed multiple food allergies. On review, she was well except for the presence of a right lower eyelid chalazion. Of note, she reported previous uneventful myopic laser insitu keratomileusis (LASIK) surgery performed bilaterally more than 10 years ago. To facilitate a comprehensive ophthalmic examination, tetracaine $1 \%\left(\mathrm{~B} \& \mathrm{~L}\right.$ Minims ${ }^{\circledR}$ ), fluorescein sodium (B\&L Fluorets), and tropicamide 1\% (B\&L Minims $^{\circledR}$ ) were administered in succession.

Shortly after the administration of topical eyedrops, she reported bilateral periorbital erythema and itchiness. Rashes

Chris H. L. Lim

chrislimmd@gmail.com

1 Department of Ophthalmology, National University Health System, Singapore, Singapore

2 Yong Loo Lin School of Medicine, National University of Singapore, Singapore, Singapore

3 Singapore Eye Research Institute, Singapore, Singapore

4 School of Optometry and Vision Science, University of New South Wales, Sydney, Australia soon developed over bilateral periorbital regions, her right cheek and right arm. Intramuscular injection of $50 \mathrm{mg}$ of diphenhydramine and oral prednisolone $30 \mathrm{mg}$ were administered. However, she subsequently developed throat and chest tightness. In view of the progression of symptoms, she was placed on continuous vitals monitoring and an intramuscular injection of $0.5 \mathrm{mg}$ of adrenaline was promptly administered. Her symptoms abated completely within halfan-hour and she was discharged well after observation and advised to follow-up with her immunologist.

Anaphylaxis is a severe and life-threatening hypersensitivity reaction affecting multiple organs or systems [5]. This is often preceded by a sensitisation phase; likely during previous LASIK surgery, where exposure to allergens triggers the formation of specific Immunoglobulin-E molecules. Upon re-exposure, cross-linking of IgE molecules occurs, causing degranulation of cells and mediator release, leading to an anaphylactic response [3].

Each previously reported patient also had a history of either allergies, atopy, or previous episodes of anaphylaxis. It is, therefore, crucial for healthcare providers administering topical eyedrops to actively enquire about these risk factors, and if identified, to consider putting patients under close monitoring and providing appropriate advice. Staff should also be trained to recognise signs and symptoms associated with anaphylaxis for prompt escalation or management while keeping in mind the possibility of anaphylaxis even in 
patients who have previously tolerated similar medications without issues.

\section{Declarations}

Conflict of interest None. This research did not receive any specific grant from funding agencies in the public, commercial, or not-forprofit sectors.

\section{References}

1. Baudouin C. Allergic reaction to topical eyedrops. Curr Opin Allergy Clin Immunol. 2005;5(5):459-63. https://doi.org/10.1097/ 01.all.0000183112.86181.9e.
2. Wahl JW. Systemic reaction to tropicamide. Arch Ophthalmol. 1969;82(3):320-1. https://doi.org/10.1001/archopht.1969.00990 020322004 .

3. Shahid H, Salmon JF. Anaphylactic response to topical fluorescein 2\% eye drops: a case report. J Med Case Rep. 2010;4:27. https:// doi.org/10.1186/1752-1947-4-27.

4. El Harrar N, Idali B, Moutaouakkil S, et al. Anaphylactic shock caused by the application of fluorescein on the ocular conjunctiva. Presse Med. 1996;25(32):1546-7.

5. Johansson SGO, Bieber T, Dahl R, et al. Revised nomenclature for allergy for global use: report of the Nomenclature Review Committee of the World Allergy Organization, October 2003. J Allergy Clin Immunol. 2004;113(5):832-6. https://doi.org/10.1016/j.jaci. 2003.12.591. 